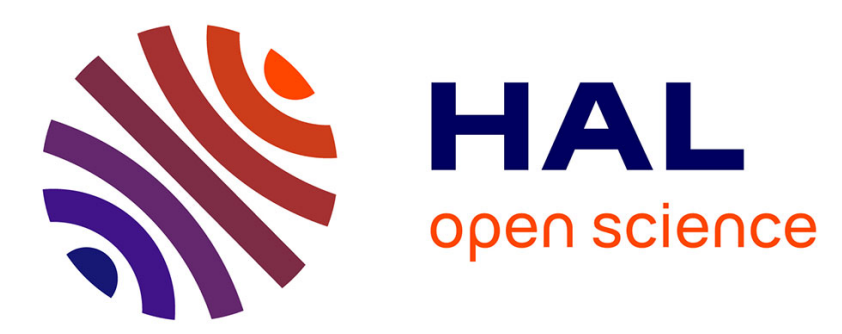

\title{
Assessment of vulnerability to erosion: digital mapping of a loess cover thickness and stiffness using spectral analysis of seismic surface-waves
}

Kevin Samyn, Olivier Cerdan, Gilles Grandjean, Romain Cochery, Séverine Bernardie, Adnand Bitri

\section{To cite this version:}

Kevin Samyn, Olivier Cerdan, Gilles Grandjean, Romain Cochery, Séverine Bernardie, et al.. Assessment of vulnerability to erosion: digital mapping of a loess cover thickness and stiffness using spectral analysis of seismic surface-waves. Geoderma, 2012, 173-174, pp.162-172. 10.1016/j.geoderma.2012.01.008 . hal-00658933

\section{HAL Id: hal-00658933 https: / hal-brgm.archives-ouvertes.fr/hal-00658933}

Submitted on 11 Jan 2012

HAL is a multi-disciplinary open access archive for the deposit and dissemination of scientific research documents, whether they are published or not. The documents may come from teaching and research institutions in France or abroad, or from public or private research centers.
L'archive ouverte pluridisciplinaire HAL, est destinée au dépôt et à la diffusion de documents scientifiques de niveau recherche, publiés ou non, émanant des établissements d'enseignement et de recherche français ou étrangers, des laboratoires publics ou privés. 
1 Assessment of vulnerability to erosion: digital mapping of a loess cover

2 thickness and stiffness using spectral analysis of seismic surface-waves

3

4 K. Samyn ${ }^{\star 1}$, O. Cerdan ${ }^{1}$, G. Grandjean ${ }^{1}$, R. Cochery ${ }^{1}$, S. Bernardie ${ }^{1}$, A. Bitri ${ }^{1}$

5

6 (1) BRGM, Risks Department, 3 Avenue Claude Guillemin, BP36009 45060 Orléans

7 Cedex 2, France

8

$9 \quad$ * Corresponding author. BRGM, Risks Department, 3 Avenue Claude Guillemin 10 BP36009 45060 Orléans Cedex 2, France. Tel.: +33 (0)2 386434 54; fax: +33

11 (0)2 386436 89. E-mail address:k.samyn@brgm.fr (K. Samyn).

12

13 Abstract

14

15 Non-invasive geophysical techniques offer an interesting alternative to 16 traditional soil sampling methods, especially for estimating spatial variations of 17 soil parameters in the landscape. The spectral analysis of seismic surface18 waves (MASW) can be used to determine the vertical shear-wave velocity $(V s)$ 19 model (i.e., vertical variations in Vs with depth). In our study, MASW soundings 20 were determined at each point in a grid spread over a wind-eroded field plot of $2115600 \mathrm{~m}^{2}$. Vs was then mapped in terms of the thickness and stiffness of the 22 superficial loamy material horizon, which are called ThickLM and StiffLM, 23 respectively. To relate the $V s$ values to the soil stiffness, cone resistance $(Q d)$ 
soundings were also performed using a Dynamic PANDA penetrometer. Concurrently, boreholes were used to sample the same horizon for bulk soil density $\left(\rho_{b}\right)$ measurements. Based on these measurements, large variations in ThickLM were observed. The distribution of $V s$ values along a $130 \mathrm{~m}$ transect allowed for the distinction between two layers corresponding to different mechanical properties. The $V s$ value of $240 \mathrm{~m} / \mathrm{s}$ was then used as a limit between the loamy material and the underlying clays. This limit was validated using drilling observations performed on the same transect. Therefore, it was possible to map the ThickLM, which varied between 0.2 and $6.5 \mathrm{~m}$ over the entire field. The comparison between the averaged values of $V s$ and $Q d$ in the loamy material layer showed a significant correlation $\left(R^{2}=0.4\right)$ such that the mapping of StiffLM was realised from the $V s$ map and the $V s-Q d$ relationship. Density comparison between the $\rho_{b}$ measured on drill samples and the $\rho_{b}$ calculated from Vs were also performed using previously published relationships; however, significant correlations were not observed. The obtained maps of ThickLM and StiffLM were consistent with the expected effects of erosion at the catchment scale and provide indications of historical erosion events. This methodology, which provides a structural and mechanical characterisation of subsurface materials, should help to focus conservation measures to the most threatened areas (i.e., the identification of areas that show a reduced ThickLM and increased StiffLM, which are associated with high soil erosion vulnerability and/or high compaction state). 


\section{$47 \quad$ Keywords}

49 Surface wave; Erosion; Digital mapping; Shear wave velocity; Cone resistance

\section{1. Introduction}

53 The current growing awareness of ecological issues has led to an increasing 54 demand for environmental datasets that are necessary for adequate monitoring 55 and management of various threatened ecosystems. There is also a growing 56 concern regarding the sustainability of biomass production, not only in 57 developing or semi-arid areas (Hadgu et al., 2009; Ye and Van Ranst, 2009) but 58 also in industrialised countries. The increasing demand for cereals and biofuels 59 will further accentuate this trend. Strong relationships between soil erosion, soil 60 depth and soil productivity have been reported in various environments (e.g., 61 Biot and Lu, 1995; Tendberg et al., 1997; Heckrath et al., 2005; Rejman and 62 Iglik, 2010). The regolith and, more generally, the soil surface material are 63 particularly important, as they support human activities and fulfil numerous 64 ecosystem services (European Commission., 2002-2006). However, our 65 knowledge of the nature and spatial extent of surficial materials is far from 66 complete, and therefore further research is necessary to fill this gap. The ability 67 to accurately and rapidly produce soil depth maps or to delineate areas with 
limited root penetration depths will, therefore, become crucial to address these issues. Conventional soil surveys are generally based on manual sampling and visual observations of soil pits or auger holes. Such observations are met with both methodological and economic constraints when used for the investigation of large areas. Not only are these observations extremely time consuming - and thus costly - because of the highly repetitive fieldwork that is needed, they can also be destructive to the soil. Moreover, this type of local observation may not represent larger-scale trends in soil properties.

Geophysical techniques offer an interesting alternative to traditional soil sampling methods, especially for estimating the spatial variability of physical soil parameters of large areas. These techniques are particularly relevant because most physical soil characteristics are closely related to soil properties (e.g., geoelectrical properties) (Rhoades and van Schilfgaarde, 1976; Robain et al., 1996; Samouëlian et al., 2005). For example, a significant correlation has been demonstrated between the apparent electrical resistivity $(\rho)$ or electrical conductivity $(\sigma)$ and the soil texture (Williams and Hoey, 1987), soil water content (Kachanoski et al., 1988; Kalinski and Kelly, 1993; Michot et al., 2003), soil salt or nutrient content (Rhoades and Corwin., 1981; Eigenberg et al., 1998) or soil depth (Thompson and Bell., 1996; Chaplot et al., 2001). In contrast to these electrical methods, seismic techniques are not well established in soil sciences but could be particularly promising. Due to the development of subsurface characterisation studies for environmental or geotechnical purposes, 
the efficiency of seismic methods for estimating ground velocity structures and mechanical properties has seen considerable progress in the recent decades and has been used in various applications in several fields: waste disposal (Lanz et al., 1998), landslides (Grandjean et al., 2007), or hydrogeophysics (Sturtevant et al., 2004). Modern equipment, which generally features 48 or 72 recording channels and PC-piloted acquisition software, has made this method user-friendly and has contributed to its popularity. Recently, an adaptation of the sensor line, which is based on unplugged gambled geophones, was proposed to drastically reduce the acquisition times (Grandjean, 2006a; Debeglia et al., 2006). This improvement was supported by the development of new data processing protocols, such as acoustical tomography (Azaria et al., 2003; Grandjean, 2006b) or spectral analysis of surface-waves (SASW) (Nazarian et al., 1983; Park et al., 2000; Grandjean and Bitri, 2006) and related multichannel MASW applications (Foti, 2000; Miller, 1999; Park et al., 1999a, 1999b; Xia et al., 1999), which allowed for the construction of shear waves velocity (Vs) profiles. For example, the analysis of fundamental-mode Rayleigh waves is one of the most common methods for using the dispersive properties of surface waves (Bullen, 1963). This type of analysis provides essential parameters that are commonly used to evaluate near-surface stiffness, which is a critical property for many geotechnical studies (Stokoe et al., 1994). SASW uses the spectral analysis of the ground roll that is generated by an impulsive source and is recorded by a pair of receivers. This method has been widely and effectively 
used in many geotechnical engineering projects (Stokoe et al., 1994). A single pair of receivers is configured and reconfigured (based on wavelength calculations made during the acquisition) as many times as necessary to sample the desired frequency range. Unfortunately, the necessity of recording repeated shots during multiple field deployments for a given site increases the time and labour requirements relative to a multichannel procedure. Multichannel analysis of surface waves (MASW) is designed to overcome the few weaknesses of the SASW method. The purpose of this study is to test the MASW method as a new tool for characterising soil mechanical properties (i.e., soil thickness and stiffness) with respect to erosion processes.

Instead of sounding the area by systematic drilling, seismic methods were tested to efficiently produce soil property maps. Specifically, we evaluated the feasibility of using mechanical contrasts that exist between the lithologies to map the thickness and stiffness (ThickLM and StiffLM, respectively) of the surface loamy material horizon using Vs data. Based on this process, we should be able to identify the most threatened areas at the catchment scale, i.e., areas that show a reduced ThickLM associated with high StiffLM, using Vs data coupled to cone resistance $(Q d)$ data because StiffLM can be used as a surrogate for the soil erodibility.

\section{Materials and methods}


The study area was located within the Bourville catchment in Normandy, a 137 region of Northern France where erosion that removes the upper soil horizons is 138 a major threat to the main soil functions (i.e., "food and other biomass 139 production, storage, filtering, and transformation of elements among which 140 water and nutrients, biological habitat, and source of raw materials", European 141 Commission, 2002; Van-Camp et al., 2004). The studied area includes a 142 catchment of the European loess belt in Normandy; this region is severely 143 affected by water and wind erosion with rates often exceeding soil production 144 (between 5 and 10 ton.ha $^{-1} \cdot \mathrm{yr}^{-1}$; Cerdan et al., 2010) (Figure 1). Normandy has 145 a humid-temperate climate with few days of frost. The average temperature 146 ranges between 10 and $12{ }^{\circ} \mathrm{C}$ throughout the year, and in August, which is the 147 hottest month of the year, the temperature fluctuates approximately $18{ }^{\circ} \mathrm{C}$. The 148 hilly areas, characterised by a smooth relief (0-7\%) and deep superficial layer 149 (>5 m), are used for intensive production of alternating winter and spring crops 150 (e.g., wheat, beets, and maize). An area of approximately 1.5 ha was selected 151 in this catchment to test our approach. Not only was this area highly degraded 152 with a quasi-complete removal of the soil cover in certain areas, its surrounding 153 areas also showed a gradation in the thickness of the loamy material horizon 154 from thick and well conserved in the low elevation locales to thin and eroded in 155 the high elevation areas. The research plot was delineated within the transition 
zone. This plot, which extended along the steepest slope (Figure 1), shows clear evidence of soil degradation in its north-west and south-east areas with the presence of outcropping clays with flints, both of which are characteristics of on-going loamy material horizon erosion. The entire soil surface was covered by grass vegetation during the field study.

\section{2. Geological setting and geomorphologic conditions}

The study area was located in north-western France (Normandy), which is characterised by a humid-temperate climate. The topography was relatively smooth with slope gradients ranging between $1 \%$ and $4 \%$ on the plateau and $4 \%$ to $10 \%$ on valley sides. The area is covered by silt loam soils, which developed on the loess Quaternary deposit, and contains at least $60 \%$ silt in the surface horizons. These soils are classified as Neoluvisol in the French Classification system and are described as 'excessively drained' according to the USDA (2003) soil drainage classification (Orthic Luvisol, World Reference Base, 1998). Such soils are very sensitive to soil sealing because of their low

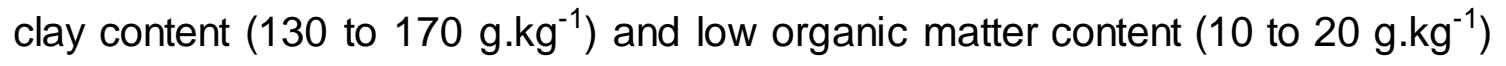
relative to more competent underlying clays that are enriched with flints. When in arable use, large areas are left bare and open to rainfall during most of the cultural season, which, combined with the sensitivity to sealing, renders them vulnerable to runoff and water erosion (Figure 2). In contrast, sediments accumulate due to erosion flows in sheltered areas. Based on the 
178 geomorphologic conditions, the thickness of the uppermost loamy sediments 179 presents a high variability at the catchment scale.

\section{3. Theory and basic principles of the MASW method}

In the majority of surface seismic surveys, when a compressional wave source is used, more than two-thirds of the total seismic energy generated is imparted 185 into Rayleigh waves (Richart et al., 1970), which is the principal component of 186 surface waves. Assuming vertical velocity variation, each frequency component 187 of a surface wave has a different propagation velocity (called the phase velocity, 188 Cf) at each unique frequency $(f)$ component. This unique characteristic results 189 in a different wavelength $(\lambda f)$ for each frequency that is propagated. This 190 property is called dispersion. Although surface waves are considered noise in 191 body-wave surveys (i.e., reflection or refraction profiling), their dispersive 192 properties can be used to infer near-surface elastic properties via Vs evaluation 193 (Nazarian et al., 1983; Stokoe et al., 1994; Park et al., 1998a). The entire 194 process typically used to produce reliable Vs profiles via the spectral analysis of 195 surface waves involves three steps: (1) the acquisition of surface waves (Figure $1963,5 \mathrm{a}$ ), (2) the construction of dispersion curves (a plot of phase velocity as a 197 function of $f$ ) (Figure 5b), and (3) the back calculation (inversion) of the Vs 198 profile from the calculated dispersion curve (Figure 5c,d). A workflow diagram 
illustrating the processing method used to obtain reliable Vs profiles with depth is presented in Figure. 4.

For step (1), to obtain a good estimation of dispersion curves, we used a multistation (MASW) configuration, in which receivers are set at several locations and are regularly spaced along a straight line. A seismic source signal was generated via the impact of a hand-held hammer hitting a small iron anvil located on the ground. During the recording, the wavefield was discretised and truncated in both the time and space domain (Figure 5a). The sampling periods in the time domain were $D t=0.5 \mathrm{~ms}$; the numbers of samples was $M=1000$. The near offset (also called origin offset; i.e., the distance between the source point and the first recording point along the line) of $x_{0}=50 \mathrm{~cm}$, the geophone spacing of $D x=50 \mathrm{~cm}$ and the offset range of $L=11.5 \mathrm{~m}$ (Figure 3) are the three important acquisition parameters that require proper selection to prevent aliasing, near field, and far field effects (Xia et al., 1999 and Miller et al., 1999). These effects determine the minimum and maximum depth in which $V s$ can be accurately measured using the MASW method. Due to certain undesirable effects, Rayleigh waves must be studied beyond the near field offset. Far from this distance, they can be considered as horizontally travelling plane waves and processed accordingly. The adaptation of MASW to soil investigations is first conditioned by the possibility of reducing the seismic array (originally consisting of several tens of meters) to approximately several meters, provided that nearfield effects are avoided. Second, the frequency range of the seismic signal is 
increased to obtain a depth of interest up to a maximum of $10 \mathrm{~m}$ below the ground surface. Finally, the selected seismic system involved a hammer source that was capable of generating signals in the 1 to few tens of $\mathrm{Hz}$ frequency range; and a seismic antenna composed of 24 geophones capable of recording signals from 10 to $200 \mathrm{~Hz}$ was used. The entire system was towed behind a vehicle (Figure 3a) to ensure a rapid acquisition. A total of 157 seismic observations were performed along 13 transects with regular $12 \mathrm{~m}$ spaces between data points, as shown in Figure 1.

For step (2), the generation of a dispersion curve is one of the most critical steps for generating an accurate Vs profile. Dispersion curves are generally displayed as $C f$ as a function of $f$ (Figure $5 b$ ). For impulsive data, a frequencydomain approach (Park et al., 1998b) is used to calculate the dispersion curve. This approach involves a 2D wavefield operation that transforms seismic data from the space-time domain into the Cf-f domain, which is more convenient for highlighting dispersion features.

For step (3), the Vs profiles were calculated using an iterative inversion process (Tarantola, 1987) that requires dispersion data (Figure 5c). A least-squares approach allows for the automation of the process (Xia et al., 1999). For the method used here, only the Vs and model thickness are updated after each iteration; Poisson's ratio remains unchanged throughout the inversion. An initial earth model needed to be specified as a starting point for the iterative inversion process. The earth model consists of velocity ( $P$-wave and $S$-wave velocity), 
density, and thickness parameters. Among these four parameters, Vs has the 244 most significant effect on the reliable convergence of the algorithm. For each 245 iteration of the inversion process, an update of Vs is calculated, and synthetic 246 dispersion curves are back calculated from this new Vs model. The synthetic 247 dispersion curve is then compared to the observed dispersion curve based on 248 the least-squares method (Figure. 5d). A reliable Vs model is obtained when the misfit between synthetic and observed dispersion curves is minimised. The inversion algorithm used in our study implements all of these aspects and is based on Hermann (1987). The stop criterion for the $C f$ residuals between synthetic and observed dispersion curves was defined as less than 5 m.s. ${ }^{-1}$. Finally, the interpolation of contiguous $V s$ models resulting from the inversion process is realised using a natural neighbour method to obtain a $2 \mathrm{D} V s$ section along the transect.

\section{4. Penetrometer soundings} with depth (Sanglerat, 1975; Burns and Mayne, 1996) by manually driving a rod 262 into the soil using a standardised hammer. Therefore, a penetrometer can be used to identify variations in soil profiles according to the penetration modulations observed on the rod at each blow of the hammer. Because this 
method is easy to use and relatively quick, this portable automatic penetrometer 266 is well adapted for detailed prospecting and mapping (Zhou, 1997). Each 267 penetrometric sounding (CPT) products a vertical cone resistance profile called 268 a penetrogram; the interpretation of the penetrogram allows for the identification 269 of different layers and that estimation of their thickness using two main criteria:

270 well-defined cone resistance thresholds and the shape of the penetrogram. $Q d$ 271 is calculated using the following relationship (Langton, 1999):

$$
Q d=\frac{1}{A} \times \frac{\frac{1}{2} M V^{2}}{e} \times \frac{1}{1+\frac{P}{M}}
$$

275 where $A$ is the cone section $\left(2 \mathrm{~cm}^{2}\right), M$ is the striking mass $(\mathrm{kg}), \mathrm{V}$ is the impact 276 velocity (ratio between the cell spacing and travel time between cells), $\mathrm{P}$ is the 277 struck mass $(\mathrm{kg})$ and $\mathrm{e}$ is the drill string progress $(\mathrm{m})$. $Q d$ soundings were 278 performed using a Dynamic PANDA penetrometer (Gourvès and Barjot, 1995) 279 along transect $n^{\circ} 5$ of the field plot with a regular spacing of $12 \mathrm{~m}$; this survey 280 was conducted at the same location as the collection of seismic data points 281 (Figure 1). In this study, we assimilated the cone mechanical resistance $Q d$ into 282 the soil stiffness. 
In addition to the abovementioned surveys, 4 drilling observations were

performed on the same transect with a spacing of $40 \mathrm{~m}$ in the midslope and 20 $\mathrm{m}$ in the footslope regions (Figure 1). Each borehole was excavated in the north-west to south-east direction to depths of $1.85 \mathrm{~m}, 3.5 \mathrm{~m}, 6 \mathrm{~m}$ and $1.7 \mathrm{~m}$. Drilling cores were used to estimate ThickLM and for laboratory measurements of the water content $(\theta)$, the real density of the solid $\left(\rho_{r}\right)$ and the bulk density (i.e., the density of the sample as a whole) $\left(\rho_{b}\right)$ in the loamy layer; these results are shown in Table 1.

\section{6. Sensitivity of Vs to soil mechanical properties}

Numerical relationships between soil mechanical properties and Vs have been previously published. One of these relationships, which is given by elastic theory and is an essential property for evaluating dynamic responses and the stiffness of soil, is the small-strain shear modulus, G (i.e., a measure of solidity). Values of $G$ are typically determined indirectly by measuring the shear wave velocity, $V s$, and the mass density of the soil, $\rho$, and computing $G=\rho V s^{2}$. Other commonly used relationships include the correlation between cone penetration resistance or SPT blow count $(\mathrm{N})$ and $\mathrm{Vs}$ and functional forms; this relationship is reported to be $V s=A . N^{S}$, where the constants $A$ and $B$ are determined by a statistical regression of a data set. A significant number of correlations have 
307 been published for various soil types. Imai and Yoshimura (1975) studied the 308 relationship between seismic velocities and certain index properties for 192 309 samples and developed empirical relationships for all soil types. Sykora and 310 Stokoe (1983) reported that geological age and type of soil are not predictive of 311 Vs, whereas the uncorrected SPT-N value is the most important term. Sykora 312 and Koester (1988) demonstrated a strong statistical correlation between the 313 dynamic shear resistance and standard penetration resistance of soils. Iyisan 314 (1996) examined the influence of the soil type on the correlation between SPT$315 \mathrm{~N}$ and $\mathrm{Vs}$ using data collected from an earthquake-prone area in the eastern 316 part of Turkey. The results showed that with the exception of gravels, the 317 correlation equations developed for all soils, sand and clay yield approximately 318 similar Vs values. Jafari et al. (2002) presented a detailed historical review of 319 the statistical correlation between SPT-N and Vs. Hasancebi and Ulusay (2006) 320 studied similar statistical correlations using 97 data pairs collected from an area 321 in the north-western part of Turkey and developed empirical relationships for 322 sands, clays, and all soils irrespective of soil type. Ulugergerli and Uyanık 323 (2007) investigated statistical correlations using 327 samples collected from 324 different areas of Turkey and defined the upper and lower bounds of an 325 empirical relationship instead of a single average curve for estimating seismic 326 velocities and relative densities.

327 These previous studies, as well as a qualitative comparison of data available on 328 our study site, demonstrate the good correlation of Vs to soil mechanical 
properties and allow for the expectation of a relatively good characterisation of StiffLM using Vs and an accurate estimation of ThickLM (Figure 6) in this context.

\section{Evaluation of ThickLM and StiffLM of the loamy material horizon}

\section{1. Relationships between Vs and CPTs}

The distribution of $V s$ values inverted along the transect $n^{\circ} 5$ allowed for the discrimination between two populations that corresponded to different mechanical properties. Each population was characterised by Gaussian laws of mean $_{1 \mathrm{st} \text { layer }}=171 \mathrm{~m} \cdot \mathrm{s}^{-1}, \sigma_{1 \mathrm{st} \text { layer }}=80 \mathrm{~m} \cdot \mathrm{s}^{-1}$ and of mean 2 nd layer $=347 \mathrm{~m} \cdot \mathrm{s}^{-1}, \sigma_{2 \mathrm{nd}}$ layer $=76 \mathrm{~m} \cdot \mathrm{s}^{-1}$, where $\sigma$ is the standard deviation (Figure 7). Moreover, the isovalue of $V s=240 \mathrm{~m} . \mathrm{s}^{-1}$ was highly consistent with the isovalue $\mathrm{Qd}=20 \mathrm{MPa}$, which marks the boundary between a soft superficial unit and a competent underlying formation (Figure 8). This observation was then used for the calibration of a Vs threshold value (VsLim $\left.=240 \mathrm{~m} \cdot \mathrm{s}^{-1}\right)$ to characterise a mechanical limit used as a criteria to map ThickLM over the entire field based on the entire seismic dataset. Finally, the mean squared error (MSE) between ThickLM observations and estimations were computed using a validation set of 4 drilling points that were positioned to be representative of the observed main variability of ThickLM. 
To study the stiffness of the loamy material-horizon, we compared Vs and Qd, obtained by CPTs, at a same depth. The two parameters can be interrelated 352 because they are both influenced by effective level of confining stress, the anisotropic $\mathrm{K}_{0}$-stress state, mineralogy, aging, bonding, and other factors 354 (Mayne and Rix, 1995; Stuedlein, 2010; Dikmen, 2009). We first applied an exclusion filter to the $V s$ data with the condition $V s<V$ sLim to restrict the analysis to the loamy layer. Then, we computed the average $Q d$ values in each

357 interval of Vs 1D models. Nugget effects on the $Q d$ data, which occur due to the 358 punctual presence of various defects (e.g., pebbles) in the medium, were previously removed from the dataset using an interpolating operator. Figure 9

360 shows the linear regression between Vs and Qd where a correlation between $361 Q d$ and $\mathrm{e}^{\mathrm{Vs}}$ is observed whith $\mathrm{R}^{2}=0.4$ and a two-tailed $\mathrm{P}$ value less than 0.0001 . 362 By conventional criteria, this difference is considered to be extremely 363 statistically significant even if samples are highly scattered. Therefore, we predicted $Q d$ according to Vs using the following equation:

368 Mapping of the spatial variation of StiffLM as a function of the average $Q d$ 369 calculated over ThickLM using Eq. (2) then becomes possible over the entire 370 field. Density comparisons between the $\rho_{b}$ measured for the drill samples and 371 the $\rho_{b}$ calculated from $V s$ using published relationships (Mayne, 2001) were 
also performed, and no significant correlations were determined. This absence of correlations was probably due to the lack of $\rho_{b}$ values for the clay formation.

\section{2. Spatial structure and interpolation of the data}

The spatial structures of ThickLM and StiffLM were assessed using variograms that were estimated in four directions at $20^{\circ}, 55^{\circ}, 110^{\circ}$ and $155^{\circ}$ from geographic north. The variograms were generated using all possible sample pairs in a given direction and by grouping these into classes (lags) of approximately equal distance (Matheron, 1965). The variances (one-half of the mean squared difference) of these paired sample measurements were then plotted as a function of the distance between samples to provide a means of quantifying the spatial structure of the data. ThickLM and StiffLM obtained using MASW and Eq. (2), respectively, were then interpolated using ordinary kriging. Ordinary kriging is a geo-statistical method that takes into account both the distance and the degree of variation between known data points and relies on the spatial correlation structure of the data to determine the weighting values. This type of kriging has been shown to provide better performance for soil parameters than other available methods (e.g., Burgess et al., 1981; Myers, 1994). The interpolations were accomplished by fitting each of several theoretical variogram models (i.e., linear, Gaussian, spherical, and exponential models) to the empirical isotropic variogram using the least-squares method. 
394 The best fit model was then used for the interpolation. Data points were 395 subsequently interpolated to a regular $2 \times 2 \mathrm{~m}$ grid using a full second-order 396 polynomial drift function, which is the common practice.

\section{Results}

Thick $L M$ ranged between 0.2 and $6.5 \mathrm{~m}$ with an average of $2.6 \mathrm{~m}$ and a median

401 of $2.7 \mathrm{~m}$ (Table 2; Figure 10a). As shown by the variogram analysis (Figure 402 11a), ThickLM exhibited a moderate anisotropy and spatial structure. 403 Nevertheless, a slight azimuth dependence of less and greater variability was 404 observed at the the $20^{\circ}$ and $110^{\circ}$ directions, respectively, relative to the other 405 directions of less and greater variability than the other directions. The 406 observations were interpolated over the $120 \times 130 \mathrm{~m}$ plot and using an 407 exponential model (sill $=0.75$; range $=4.5 \mathrm{~m}$ ) coupled with a Gaussian model 408 (sill $=9$; range $=70 \mathrm{~m})$. The interpolated ThickLM map showed a gradual 409 increase in thickness from the north-west limit of the plot, where values were 410 approximately $0.20 \mathrm{~m}$, to the mid-plot position; a gradual decrease was then 411 observed from the mid-plot position to the south-east limit, where ThickLM was 412 approximately the same as on the north-west side (Figure 10a). An area of 413 greater ThickLM (between 3 and $6.5 \mathrm{~m}$ ) was observed at the mid-plot position. 414 A local area of greater ThickLM (between 1.5 and $3 \mathrm{~m}$ ) was observed on the 415 north-west side of the plot. The differences between the observed and 
estimated ThickLM values are shown in Figure 12. The MSE of $0.043 \mathrm{~m}$ and $\mathrm{R}^{2}=0.956$ between these two variables over the 4 validation points shows that the estimated ThickLM could be considered to be accurate based on the consideration that the drilling observations are determined to be representative of the overall observed variability of ThickLM over the entire plot.

StiffLM, which is related to the mean $Q d$ calculated over ThickLM, ranged between 2 and $6 \mathrm{MPa}$ with an average of $3.78 \mathrm{MPa}$ and a median of $3.68 \mathrm{MPa}$ (Table 2; Figure 10b). As demonstrated by the variogram analysis (Figure 11b), StiffLM exhibited a moderate anisotropy and spatial structure. Anisotropy was observed between the 20 and $110^{\circ}$ directions with less and greater variability than the other directions. The observations were interpolated over the $120 \times 130$ $\mathrm{m}$ plot using a Gaussian model (nugget $=0.1$; sill $=0.7$; range $=50 \mathrm{~m}$ ). The interpolated StiffLM map showed a gradual decrease in stiffness from the northwest limit of the plot, where the values range between 5 and $6 \mathrm{MPa}$, to the midplot position; a gradual increase from mid-plot position to the south-east limit, where StiffLM presented an lower stiffness than on the north-west side, was also observed (Figure 10b). An area of lower StiffLM (between 2 and $4 \mathrm{MPa}$ ) was observed at the mid-plot position. A local zone of lower StiffLM (approximately $4 \mathrm{MPa}$ ) was observed in the north-west side of the plot.

\section{Discussion}


438 The maps of ThickLM and StiffLM were in good agreement with the expected 439 consequences of the on-going erosion of the loamy material horizon: a 440 gradation in the thickness of the loamy material-horizon from thick and well 441 conserved in the lower parts to thin and eroded in the upper parts, was 442 observed (Figure 10a). The increase of StiffLM at the limits of the study plot 443 shows clear evidence of soil degradation in the north-western and south444 eastern zones with the presence of bare soils and outcropping clays and flints, 445 which have a mechanical resistance. The local event of greater ThickLM and 446 lower StiffLM indicated on Figures 10a and 10b with a black dotted line should 447 correspond to a buried former gully that was photographed at this location 2 448 years prior to the study and was caused by strong runoff activity (Figure 10c). 449 This structural and mechanical characterisation of the loamy material horizon 450 should not only help to focus conservation measures in the most threatened 451 areas (i.e., areas that show a reduced ThickLM and increased StiffLM 452 associated with high soil erosion vulnerability and/or a high compaction state), 453 but will also help identify historical erosion events. The combination of maps of 454 soil stiffness and surficial sediment depths will allow the development and 455 implementation of soil conservation measures to target high-priority areas. 456 Where climatic scenarios are available, these maps can also be used to 457 calculate the potential productivity loss using simulators, such as the 458 SimPLE.ca model (Bremer et al., 2008). This method will also contribute to the 459 broad discussion of reducing the inherent uncertainty in current soil mapping or 
460 attribute determinations. Soil maps show that there can be considerable 461 uncertainty in map unit composition with resulting spatial variability in soil 462 properties within map units (Webb and Lillburne, 2005). Actual soil maps define 463 discrete soil classes, which represent the interpolation of only a limited number 464 of modal soil profiles without capturing the full extent of soil variability (Campbell 465 and Edmonds, 1984; Qi and Zhu, 2011). In the study presented here, the non466 destructive mapping of continuous soil properties in space will help to improve 467 the data frequency and allow for the derivation of probability distributions to 468 parameterise the fuzzy nature of the geographical objects that comprise the soil 469 maps (Martin-Clouaire et al., 2000).

\section{Conclusions}

474

475 The objective of this study was to test and validate a new geophysical technique 476 for mapping soil properties that are related to soil erosion processes. A seismic 477 experiment coupled with penetrometric measurements form the basis of the proposed methodology. The MASW method was efficient for producing Vs 479 models over large areas. When coupled with penetrometric measurements of 480 Qd variations with depth, high-resolution maps of soil thickness and stiffness 
481 482 Qd.

483 We demonstrated that accurate mapping of variations in the thickness and 484 stiffness of the loamy material horizon can be obtained by integrating 485 information on the relationship between seismic Vs, soil mechanical resistance 486 and drilling observations into the mapping process. An analysis of the 487 correlation between seismic Vs and soil mechanical behaviours provided an 488 effective basis for the accurate delineation of a specific soil attribute. According 489 to the discussion, the analysis of the correlation between the seismic shear 490 wave velocity and the soil bulk density at an interface of strongly contrasted 491 mechanical properties should be studied further.

492 The future of precise mapping of selected soil properties using geophysical 493 seismic techniques in dependent on the understanding of relationships between 494 geophysical signals obtained from this technology and the overall spatial and 495 temporal variability of soil patterns. As the value of the soil resources and 496 associated ecological services receive greater recognition, digital soil mapping 497 based on seismic shear wave velocity can provide spatial data regarding soil 498 degradation that will serve as an essential tool for soil conservation and/or soil 499 rehabilitation.

500

501

\section{Acknowledgements}

502 
503 This study was funded by the FP7-DIGISOIL project. The DIGISOIL project 504 (FP7-ENV-2007-1 N²11523) is financed by the European Commission under 505 the 7th Framework Programme for Research and Technological Development, 506 Area "Environment", Activity 6.3 "Environmental Technologies". The authors 507 thank J. F. Ouvry from AREAS for his help in focusing the study field and Alexis 508 Rochat for his help in acquiring field seismic data. Finally, the authors thank the 509 editors of Geoderma and two anonymous reviewers for their comments and 510 suggestions that led to an improved version of the manuscript.

\section{References}

Afnor, Norme française NF XP P 94-105, Essai de pénétration dynamique à énergie variable, Association française de normalisation, 2000.

Azaria, A., C. Zelt, A. Levander, 2003. High-resolution seismic mapping at a groundwater contamination site: 3-D traveltime tomography of refraction data, EGS-AGU-EUG Joint Meeting, Nice, France.

Biot Y, Lu X.X. 1995. Loss of yield caused by soil erosion on sandy soils in the UK, Soil use and Management 11 (4)157-162.

Bremer E., Black M., Townley-Smith L., Malhi SS., Izaurralde RC., Larney FJ. 2008. SimPLE.ca: Simulator of productivity loss due to erosion for Canada, Canadian Journal of Soil Sciences 88 (3) 365-376. 
524 Bullen, K. E., 1963, An introduction to the theory of seismology: Cambridge 525 Univ. Press.

526 Burgess, T., Webster, R., McBratney, A., 1981. Optimal interpolation and 527

Burns, S.E., Mayne, P.W., 1996. Small and high-strain measurements of in-situ soil properties using the seismic cone penetrometers. TRR 1548 SmallMagnitude Measurements in Geotechnical Engineering. National Academy Press, pp. 81-88.

J.B. Campbell and W.J. Edmonds, 1984. The missing geographic dimension to soil taxonomy. Annals of the Association of American Geographers, 74 (1984), pp. 83-97.

Cerdan O., G. Govers, Y. Le Bissonnais, K. Van Oost, J. Poesen, N. Saby, A. Gobin, A. Vacca, J. Quinton, K. Auerswald, A. Klik, F.J.P.M. Kwaad, D. Raclot, I. lonita, J. Rejman, S. Rousseva, T. Muxart, M.J. Roxo, T. Dostal. 2010. The rate and spatial distribution of soil erosion in Europe, Geomorphology 122, 167-177.

Chaplot, V., Walter, C., Curmi, P., Hollier-Larousse, A., 2001. Mapping fieldscale hydromorphic horizons using Radio-MT electrical resistivity. Geoderma 102, 61-74. 
544 Debeglia N., Bitri A., Thierry P., 2006. Karst investigations using microgravity and MASW; Application to Orléans, France. Near Surface Geophysics, 4, 215-225.

Dikmen, U., 2009. Statistical correlations of shear wave velocity and penetration resistance for soils. Journal of Geophysics and Engineering, volume 6, number 1 .

Eigenberg, R.A., Korthals, R.L., Neinaber, J.A., 1998. Geophysical electromagnetic survey methods applied to agricultural waste sites. J. Environ. Qual. 27, 215-219.

European Commission (2002). Towards a strategy for soil protection, COM (2002) 179 final. Internet:http://europa.eu.int/comm/environment/ agriculture/soil_protection.htm.

European Commission. 2006. Thematic Strategy for Soil Protection, COM(2006)231 final. Internet: http://eur-lex.europa.eu/LexUriServ/Lex UriServ.do?uri=COM:2006:0231:FIN:EN:PDF

Foti, S., (2000) Multistation Methods for Geotechnical Characterization using Surface-waves, Dottorato di Ricerca in Ingegneria Geotecnica.

Gourvès, R., Barjot, R., 1995. Le pénétromètre dynamique léger Panda. Comptes rendus, 11ème congrès Européen de Mécanique des Sols et des Travaux de Fondations, Copenhague, vol. 3, 83-88. 
Grandjean G. and Bitri A., (2006) 2M-SASW: inversion of local Rayleigh wave dispersion in laterally heterogeneous subsurfaces: application to SuperSauze landslide (France). Near Surface Geophysics,, 367-375.

Grandjean, G., 2006a. A seismic multi-approach method for characterizing contaminated sites. J. Applied Geophys., 58, 87-98.

Grandjean G., 2006b. Imaging subsurface objects by seismic P-wave tomography: numerical and experimental validations. Near Surface Geophysics, 275-283.

Grandjean, G., Malet, J.P., Bitri, A., and Meric O., 2007. Geophysical data fusion by fuzzy logic for imaging mechanical behaviour of mudslides. Bull. Soc. Geol. France, 177, 2, 133-143.

Hadgu KM., Rossing WAH., Kooistra L., van Bruggen AHC. 2009. Spatial variation in biodiversity, soil degradation and productivity in agricultural landscapes in the highlands of Tigray, northern Ethiopia, Food Security 1 (1) 83-97.

Hasancebi, N. and Ulusay, R. (2006). "Empirical correlations between shear wave velocity and penetration resistance for ground shaking assessments," Bull Eng Geol Environ, 66, 203-213.

Heckrath G, Djurhuus J, Quine TA, Van Oost K, Govers G, Zhang Y. 2005. Tillage erosion and its effect on soil properties and crop yield in Denmark, Journal of Envirnmental Quality 34 (1) 312-324. 
Hermann, R.B., 1987. Computer programs in seismology. Saint-Luis University, USA.

Imai, T. and Yoshimura, Y. (1975). "The relation of mechanical properties of soils to P and S-wave velocities for ground in Japan," Technical Note, OYO Corporation.lyisan, R. (1996). "Correlations between shear wave velocity and in-situ penetration test results," Tech. J. Chamber Civil Eng. Turkey, 7, 1187-99 (in Turkish).

Jafari, M. K., Shafiee, A. and Ramzkhah, A. (2002). "Dynamic properties of the fine grained soils in south of Tehran," J. Seismol. Earthq. Eng., 4, 25-35.

Kachanoski, R.G., Gregorich, E.G., Van Wesenbeeck, J., 1988. Estimating spatial variations of soil water content using noncontacting electromagnetic inductive methods. Can. J. Soil Sci. 68, 715-722.

Kalinski, R.J., Kelly, W.E., 1993. Estimating water content of soils from electrical resistivity. Geotech. Test. J. 16, 323-329.

Langton, D. D., 1999. The PANDA lightweight penetrometer for soil investigation and monitoring material compaction, Ground Engineering.

Lanz, E., Mauer, H., Green, A.G., 1998. Refraction tomography over a buried waste disposal site. Geophysics 63, 1414-2007-02-21.

Lunne, P., Robertson, P. KK., and Powell, J. J. M., 1997, Cone penetration testing in geotechnical practice. E and FN SPON. 
Martin-Clouaire R., Cazemier D.R., Lagacherie P. 2000. Representing and processing uncertain soil information for mapping soil hydrological properties Computers and Electronics in Agriculture 29 (1-2), 41-57

Matheron, G., 1965. Les variables régionalisées et leur estimation: une application de la théorie de fonctions aléatoires aux sciences de la nature. Masson et Cie, Paris. 306 pp.

Mayne, P.W., 2001, Stress-strain-strength-flow parameters from enhanced insitu tests, Proceedings of the International Conference on In-Situ Measurement of Soil Properties and Case Histories, Bali, pp. 27-48.

Mayne, P. W., Rix, G. J., Correlations between shear wave velocity and cone tip resistance in natural clays, Soil and Foundations 35 (1995) (2), pp. 107110.

McMechan G. A., Yedlin M. J., 1981, Analysis of dispersive waves by wave field transformation. Geophysics vol. 46 p. 869-874.

Michot, D., Benderitter, Y., Dorigny, A., Nicoullaud, B., King, D., Tabbagh, A., 2003. Spatial and temporal monitoring of soil water content with an irrigated corn crop cover using electrical resistivity tomography. Water Resour. Res. 39, 11-38.

Miller, R.D., Xia, J., Park, C.B., and Ivanov, J.M., 1999, Multichannel analysis of surface waves to map bedrock: The Leading Edge, 18, 1392-1396.

Myers, D.E., 1994. Spatial interpolation: an overview. Geoderma 62, 17-28. 
Nazarian, S., Stokoe,K. H., II, and Hudson,W. R., 1983, Use of spectral analysis of surface waves method for determination of moduli and thicknesses of pavement systems: Transport. Res. Record, 930, 38- 45.

Papy F, Douyer C. 1991. Influence des états de surface du territoire agricole sur le déclenchement des inondations catastrophiques. Agronomie 11:201-215.

Park, C.B., Miller, R.D., Xia, J., Ivanov, J., 2000. Multichannel seismic surfacewave methods for geotechnical applications. Proc. of the First Int. Conf. on the App. of Geophys. Methodologies to Transportation Facilities and Infrastructure, St. Louis, December 11-15.

Park, C.B., Miller, R.D., and Xia, J., 1999a, Multimodal analysis of high frequency surface waves: Proceedings of the symposium on the application of geophysics to engineering and environmental problems '99, $115-121$.

Park, C.B., Miller, R.D., and Xia, J., 1999b, Multichannel analysis of surface waves: Geophysics, 64, 800-808.

Park, C. B., Xia, J., and Miller, R. D., 1998a, Ground roll as a tool to image near-surface anomaly: 68th Ann. Internat. Mtg., Soc. Expl. Geophys., Expanded Abstracts, 874-877.

Park, C. B., Xia, J., and Miller, R. D., 1998b, Imaging dispersion curves of surface waves on multichannel record: 68th Ann. Internat. Mtg., Soc. Expl. Geophys., Expanded Abstracts, 1377-1380. 
Qi F., Zhu A-X. 2011. Comparing three methods for modeling the uncertainty in knowledge discovery from area-class soil maps Computers \& Geosciences 37 (9), 1425-1436

Rejman J., I. Iglik. 2010. Topsoil reduction and cereal Yields on loess soils of Southeast Poland Land Degrad. Develop. 21: 401-405.

Richart, F. E., Hall, J. R., and Woods, R. D., 1970, Vibrations of soils and foundations: Prentice-Hall, Inc.

Rhoades, J.D., Corwin, D.L., 1981. Determining soil electrical conductivitydepth relations using inductive electromagnetic soil conductivity meter. Soil Sci. Soc. Am. J. 45, 255-260.

Rhoades, J.D., van Schilfgaarde, J., 1976. An electrical conductivity probe for determining soil salinity. Soil Sci. Soc. Am. J. 40, 647-651.

Robain, H., Descloitres, M., Ritz, M., Atangana, Q.Y., 1996. A multiscale electrical survey of a lateritic soil system in the rain forest of Cameroon. J. Appl. Geophys. 34, 237-253.

Samouëlian, A., Cousin, I., Tabbagh, A., Bruand, A., Richard, G., 2005. Electrical resistivity survey in soil science: a review. Soil Tillage Res. 83, 173-193.

Sanglerat. G, The penetrometer and soil exploration, Elsevier, 1975.

Stokoe, K. H., II, Wright, G. W., James, A. B., and Jose, M. R., 1994, Characterization of geotechnical sites by SASW method, inWoods, R. D., Ed., Geophysical characterization of sites: Oxford Publ. 
Stuedlein, A. W., 2010. Shear-wave velocity correlations for Puyallup River alluvium, J. Geotech. and Geoenvir. Engrg. 136, 1298 (2010 ); doi:10.1061/(ASCE)GT.1943-5606.0000342 (7 pages)

Sturtevant, K. A., Baker, G. S., Snyder, C., Kopczynski, S., 2004. Hydrogeophysical characterization of bedrock fracture orientations using azimuthal seismic refraction tomography. AGU, H23A-1122.

Sykora, D. E. and Stokoe, K. H. (1983). "Correlations of in-situ measurements in sands of shear wave velocity," Soil Dyn. Earthq. Eng., 20, 125-36.

Sykora, D. W. and Koester, P. J. (1988). "Correlations between dynamic shear resistance and standard penetration resistance in soils," Earthq. Eng. Soil Dyn., 2, 389-404.

Tarantola, A., 1987, Inverse problem theory. Elsevier Science Publishing Co., Inc.

Tengberg A, Stocking M, Dechen SCF. 1997. The impact of erosion on soil productivity - An experimental design applied in Sao Paulo State, Brazil, Geografiska Annaler Series A, Physical Geography 79A (1-2) 95-107.

Thompson, J.A., Bell, J.C., 1996. Color index for identifying hydric conditions for seasonally saturated mollisols in Minnesota. Soil Sci. Soc. Am. J. 60, 1979-1988.

Ulugergerli, U. E. and Uyanik, O. (2007). "Statistical correlations between seismic wave velocities and SPT blow counts and the relative density of soils," J. Test. Eval., 35, 1-5. 
U.S. Department of Agriculture, 2003. National Soil Survey Handbook, title 430 -

VI. [Online] Available: bhttp:// soils.usda.gov/technical/handbook/N.

Van-Camp. L., Bujarrabal, B., Gentile, A-R., Jones, R.J.A., Montanarella, L., Olazabal, C. and Selvaradjou, S-K. (2004). Reports of the Technical Working Groups Established under the Thematic Strategy for Soil Protection. EUR 21319 EN/1, 872 pp. Office for Official Publications of the European Communities, Luxembourg.

Webb, TH, Lillburne, LR. 2005 Consequences of soil map unit uncertainty on environmental risk assessment AUSTRALIAN JOURNAL OF SOIL

\section{RESEARCH 43 (2), 119-126}

Williams, B.G., Hoey, D., 1987. The use of electromagnetic induction to detect the spatial variability in the salt and clay content of soils. Austr. J. Soil Res. $25,21-27$.

World Reference Base, 1998. World Reference Base for Soil Resources. FAO, World Resources Report no. 84, Rome, Italy.

Xia, J., Miller, R.D., and Park, C.B., 1999, Configuration of near surface shear wave velocity by inverting surface wave: Proceedings of the symposium on the application of geophysics to engineering and environmental problems' 99 , 95-104.

Ye L., Van Ranst E. 2009. Production scenarios and the effect of soil degradation on long-term food security in China, Global Environmental Change 19 464-481. 
713 Zhou. S, Caractérisation des sols de surface à l'aide du pénétromètre 714 dynamique léger à énergie variable type Panda, thèse, université Blaise715 Pascal, Clermont-Ferrand-2, 1997, $179 \mathrm{p}$. 
719 Table 1 . Soil properties for 4 drilling observations along the $n^{\circ} 5$ transect with a 720 721 722 723

724 Table. 2. General statistics (Min: minimum; Max: maximum; Av: average; 725 Median; Stdev, standard deviation; Var: variance; CV, coefficient of variation; 726 Skwe, skewness; Kurt, kurtosis for ThickLM, which is the thickness of the loamy 727 material horizon (m); Qd: the mechanical resistance (MPa). 


\section{Figure captions}

Figure 1. Location of the study plot within the Bourville catchment in Normandy, a region of Northern France. Contour lines of absolute altitude with $0.5 \mathrm{~m}$ intervals within the $120 \times 130 \mathrm{~m}$ plot are presented for the 157 data points of the seismic survey. Position of the 4 drilling events and the 12 penetrometer soundings are indicated along the $n^{\circ} 5$ transect.

Figure 2. Loamy sediments showing the critical thickness are rendered more vulnerable to runoff and water erosion relative to competent and nearly outcropping clays enriched with flints.

Figure 3. a) Photograph of the towing system with the seismic acquisition central and laptop computer. b) Photograph of the seismic array with 24 geophones regularly spaced at $50 \mathrm{~cm}$. c) Schematic representation of the acquisition configuration with the key parameters: near offset $x 0$, geophone spacing $D x$ and offset range $L$.

Figure. 4. Workflow diagram illustrating the methodology using to obtained reliable Vs versus depth models. 
750 Figure 5. a) Example of recorded surface waves. b) Observed dispersion curve 751 obtained by Cf- $f$ domain transformation. c) Comparison between the initial and 752 final Vs versus depth model obtained after the inversion step. d) Comparison 753 between observed and synthetic dispersion curves. The relatively good fit 754 between these curves indicates the reliability of the final model.

755 Figure 6. Qualitative comparison between a drilling observation, a penetrometer 756 sounding and a Vs versus depth model at the same location. The relatively 757 good correlations between Vs, mechanical properties of the soil and the 758 observed lithologies are shown.

760 Figure 7. Representation of the Vs distribution. Two populations characterised by Gaussian laws of mean $_{1 \mathrm{st} \text { layer }}=171 \mathrm{~m} \cdot \mathrm{s}^{-1}, \sigma_{1 \mathrm{st} \text { layer }}=80 \mathrm{~m} \cdot \mathrm{s}^{-1}$ and of $\operatorname{mean}_{2 \mathrm{nd}}$ 762 layer $=347 \mathrm{~m} \cdot \mathrm{s}^{-1}, \sigma_{2 n d}$ layer $=76 \mathrm{~m} \cdot \mathrm{s}^{-1}$ are distinguished.

764 Figure 8. Seismic and penetrometric sections along transect $n^{\circ} 5$. Threshold values of $\mathrm{Vs}=240 \mathrm{~m} / \mathrm{s}$ and $\mathrm{Qd}=20 \mathrm{MPa}$ overlay the sections in black dotted line 766 and red solid line, respectively. Drilling observations overlay the seismic section 767 in black crosses. There is a good agreement, in terms of ThickLM, between the 768 threshold values and ThickLM obtained from drilling observations. 
770 Figure. 9. Observed $V s$ after exclusion filtering $(V s>240 \mathrm{~m} / \mathrm{s})$ versus averaged 771 interpolated $Q d$ computed for the thicknesses of $V s$ intervals on $1 \mathrm{D}$ models 772 along the $n^{\circ} 5$ transect.

Figure 10. a) Spatial variations in the thickness of the loamy material horizon (ThickLM) obtained using MASW. b) Spatial variations in the stiffness of the loamy material horizon (StiffLM) obtained using Eq. (2). Contour lines of absolute altitude with a $0.5 \mathrm{~m}$ interval overlay the map. The 4 drilling observations, 12 penetrometric data points and 157 seismic data points are shown on the map. The black dotted line represents the buried former gully that is visible in the photograph. c) Photograph showing the buried former gully.

Figure 11. a) Directional variogram of ThickLM. b) Directional variogram of StiffLM.

Figure 12. Plot of estimated ThickLM values obtained using the MASW methodology and the observed ThickLM for the 4 drilling observations. 
Figure 1

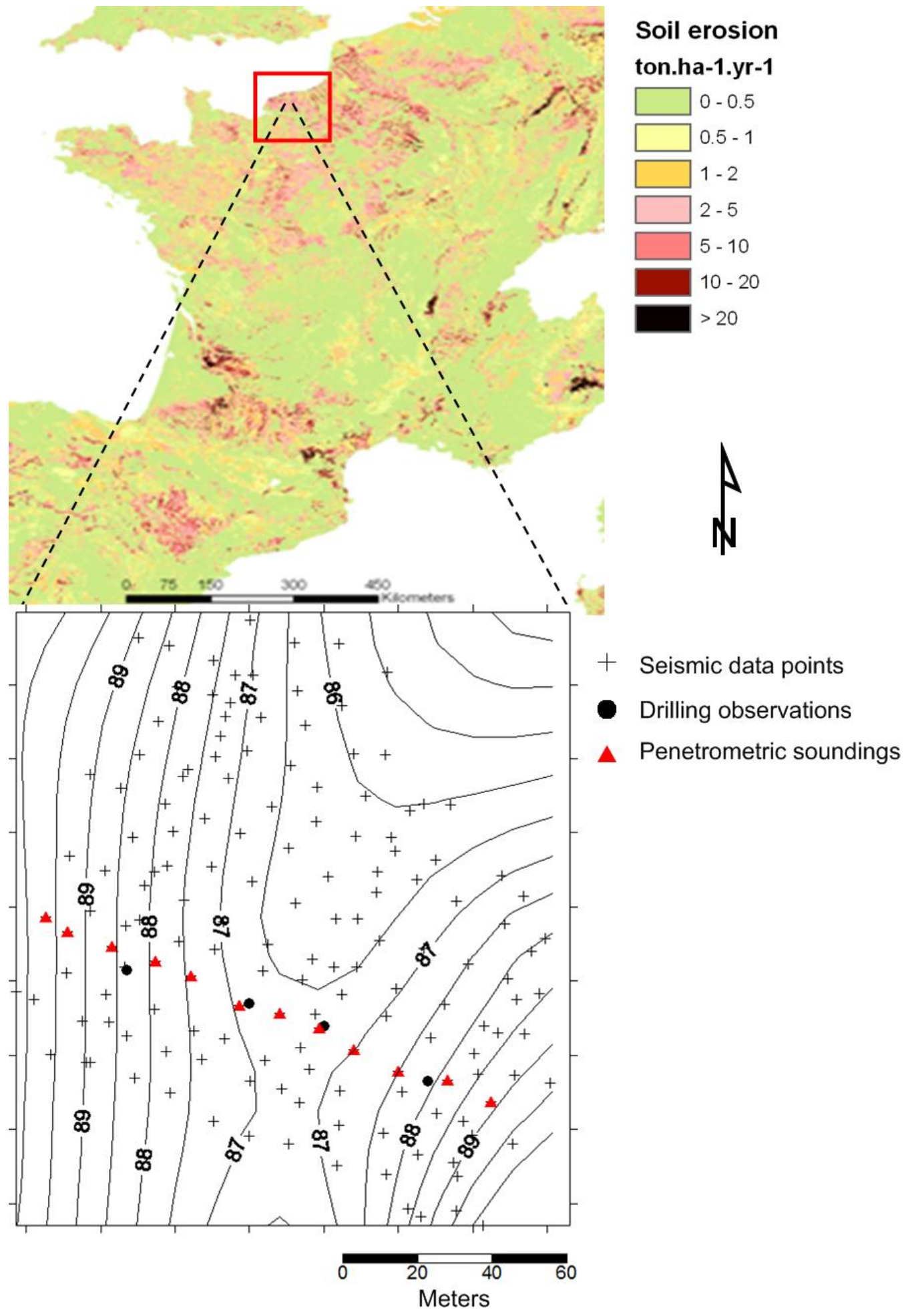


$794 \quad$ Figure 2

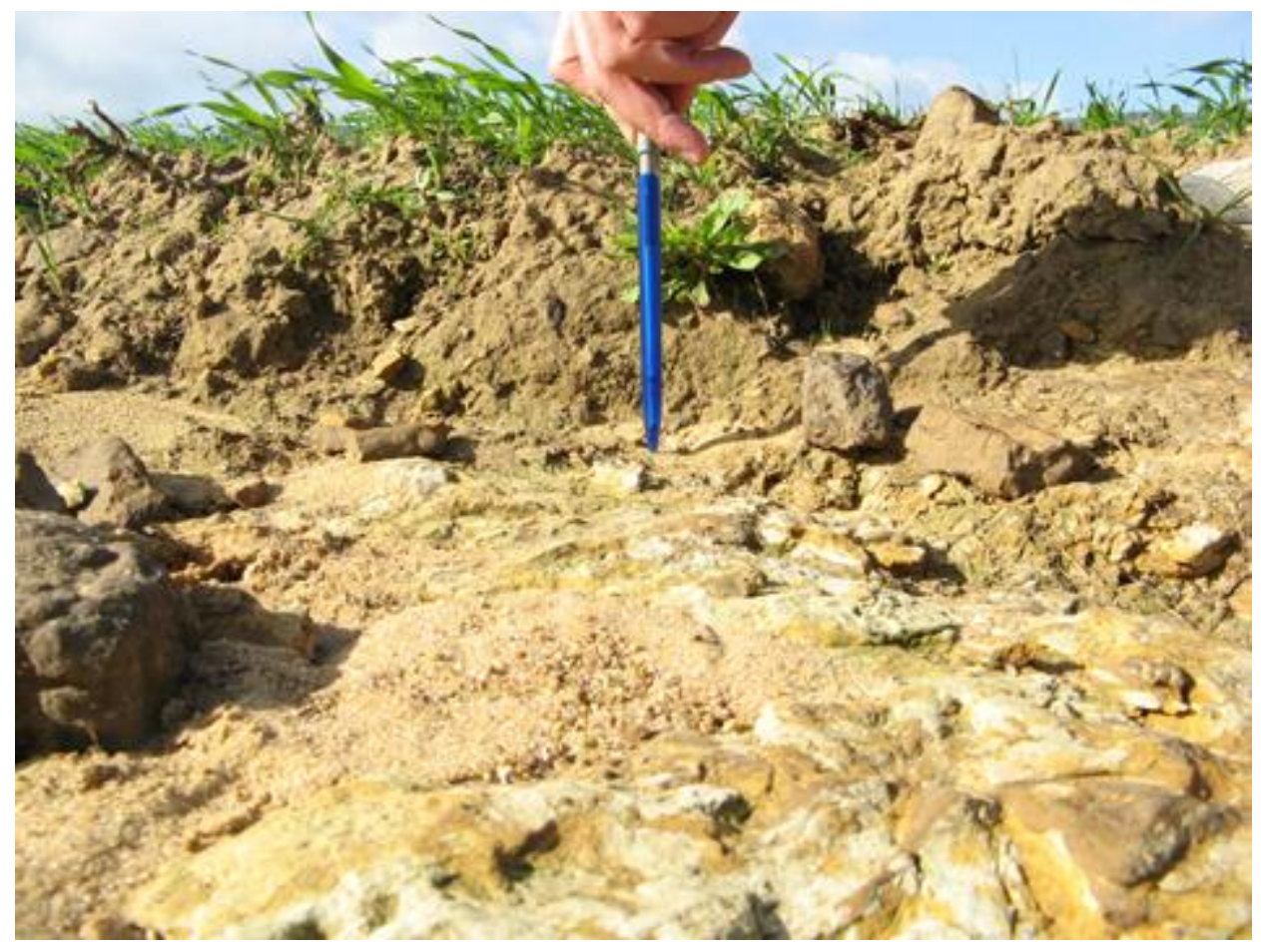

796 
797 Figure 3

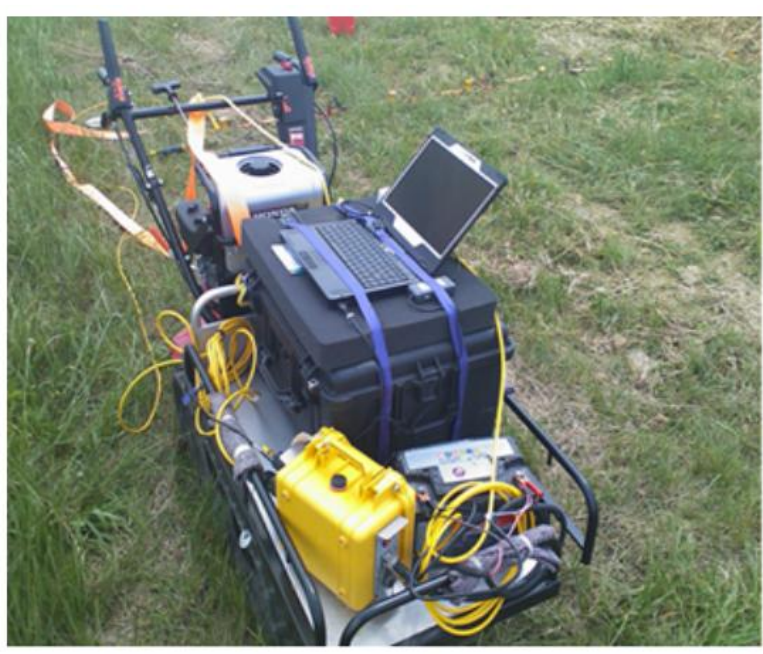

a)

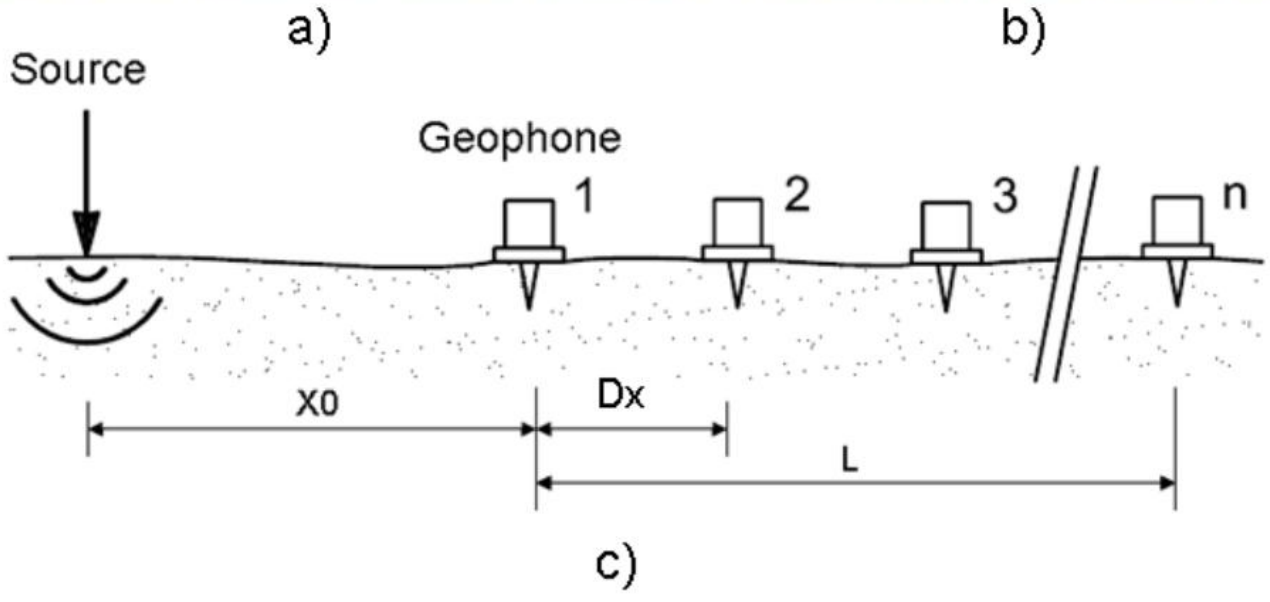

c)

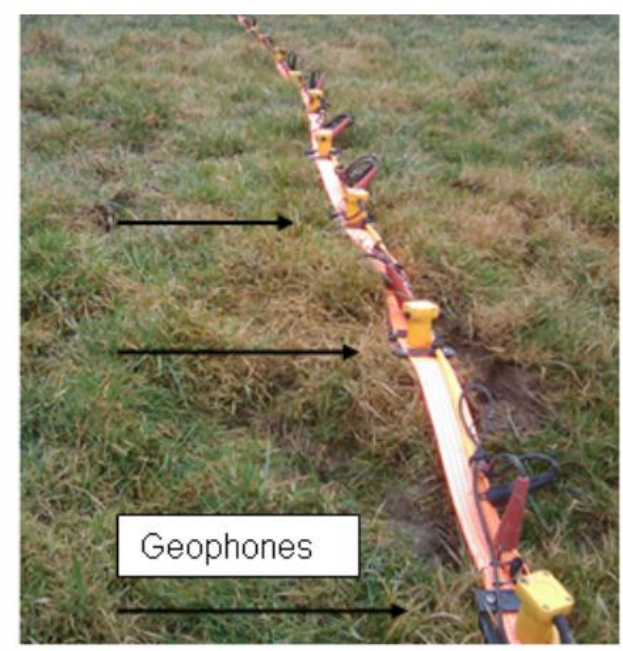

b)

798

799 


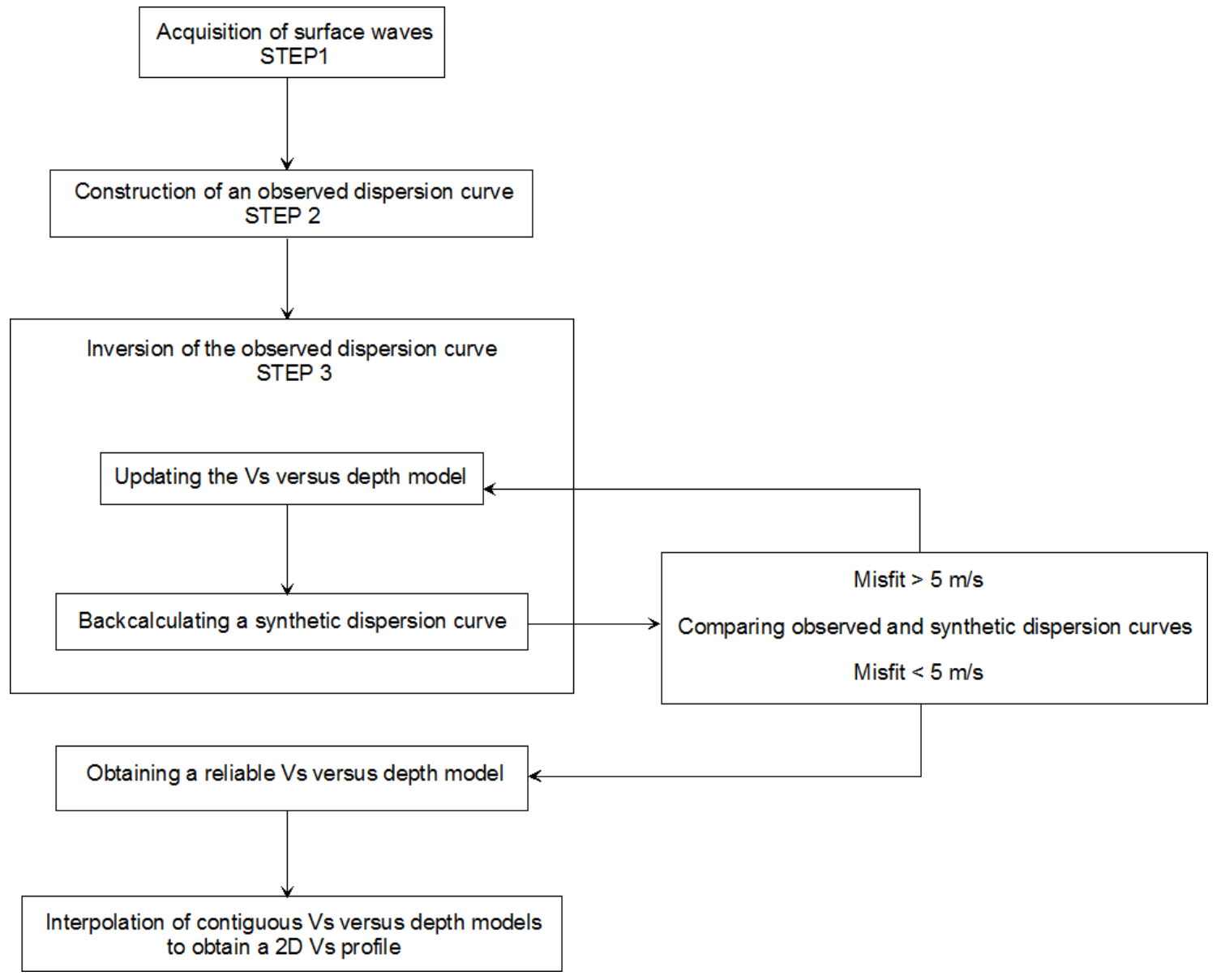


Figure 5

a)
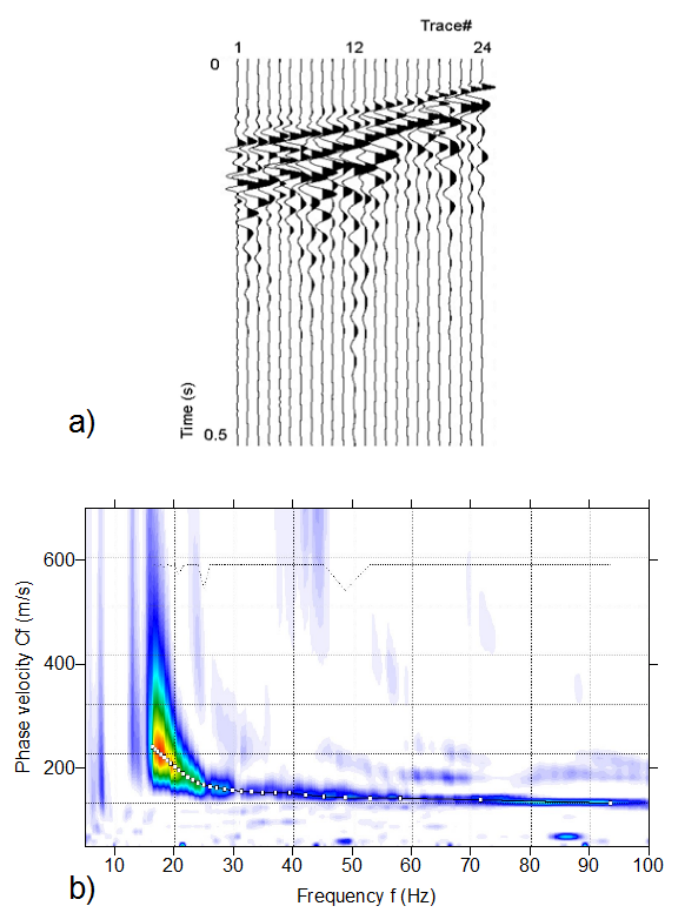

$\square$ Observed dispersion curve
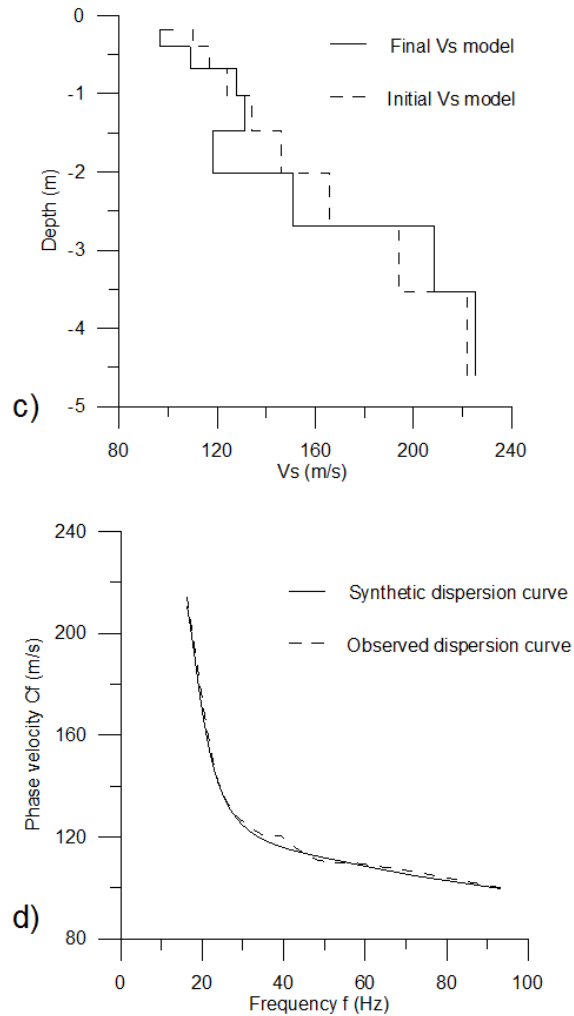

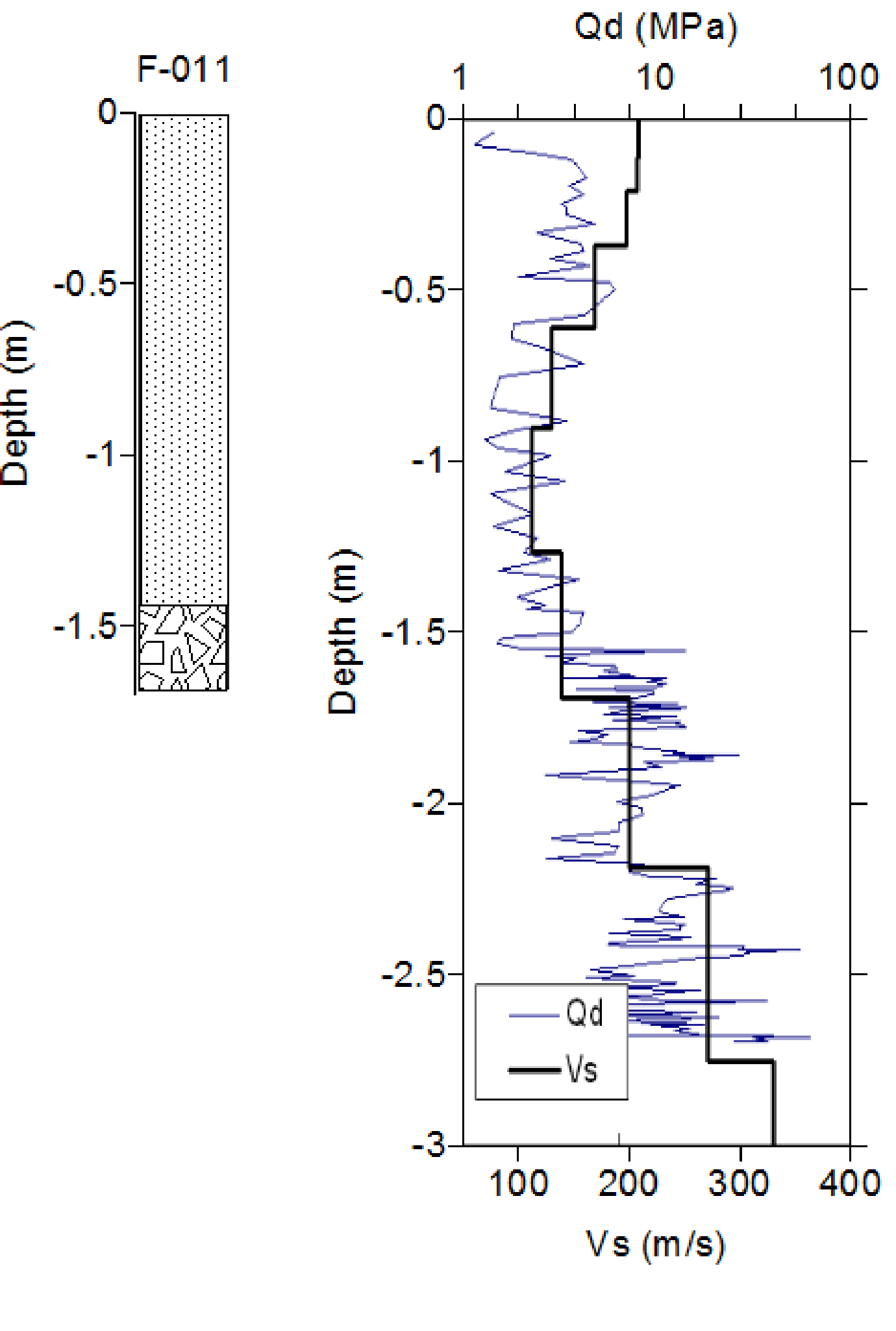
Figure 7

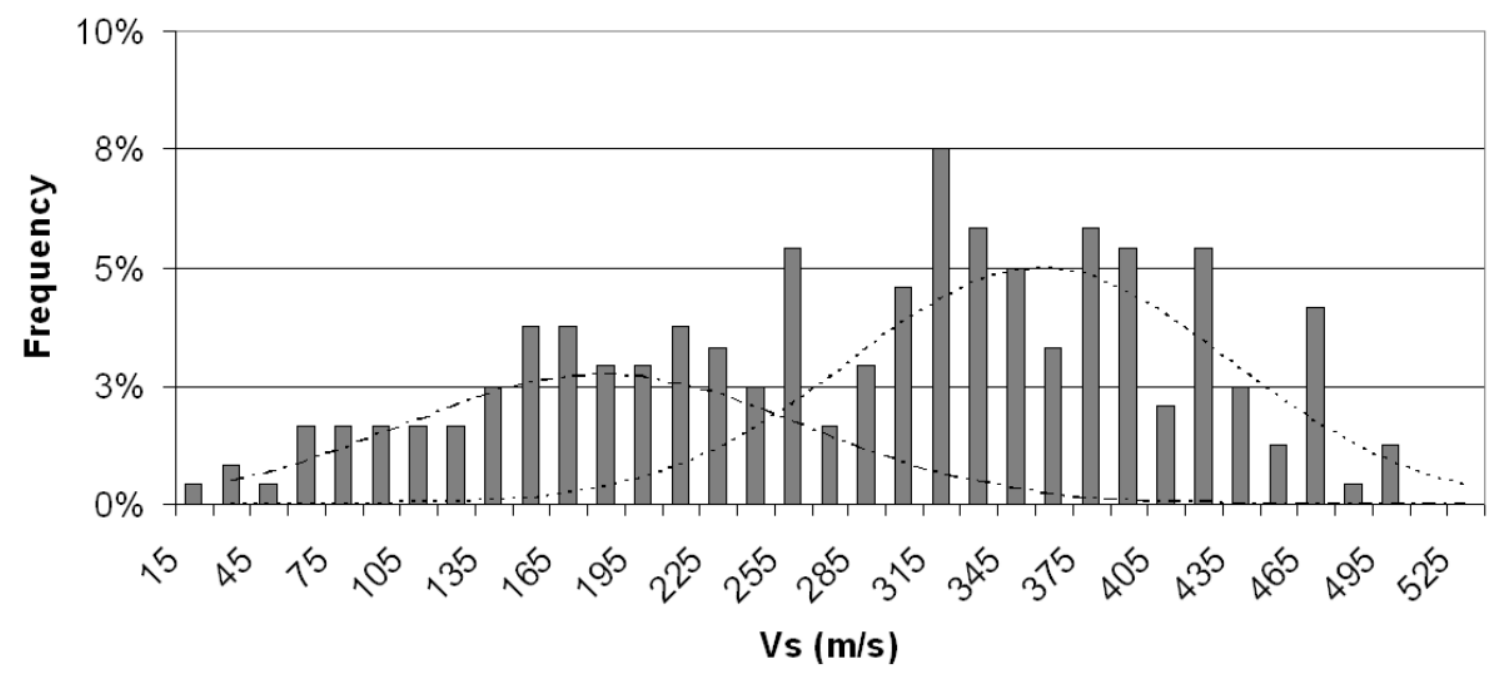

810

$\square$ Vs frequency -..- 1st layer ...... 2nd layer

811 
812 Figure 8

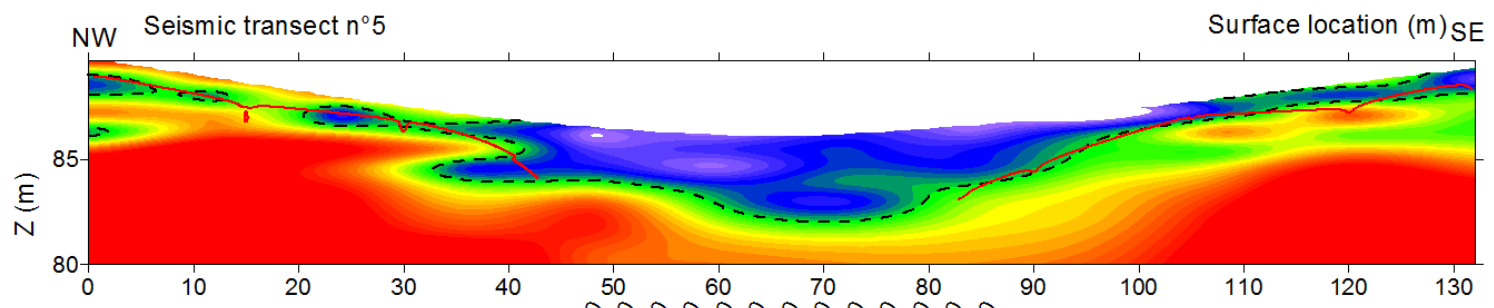
3

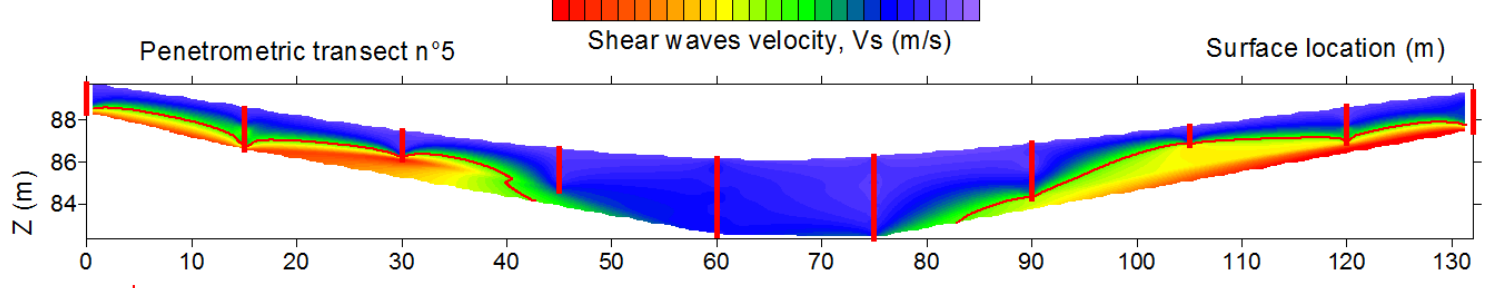

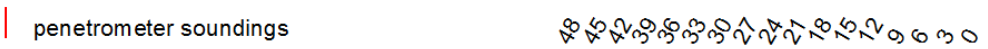

813

f drilling observations with observed ThickLM

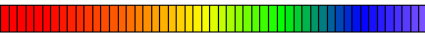

- $\mathrm{Qd}=20 \mathrm{MPa}$

Cone resistance, $\mathrm{Qd}(\mathrm{MPa})$

814 
815 Figure 9

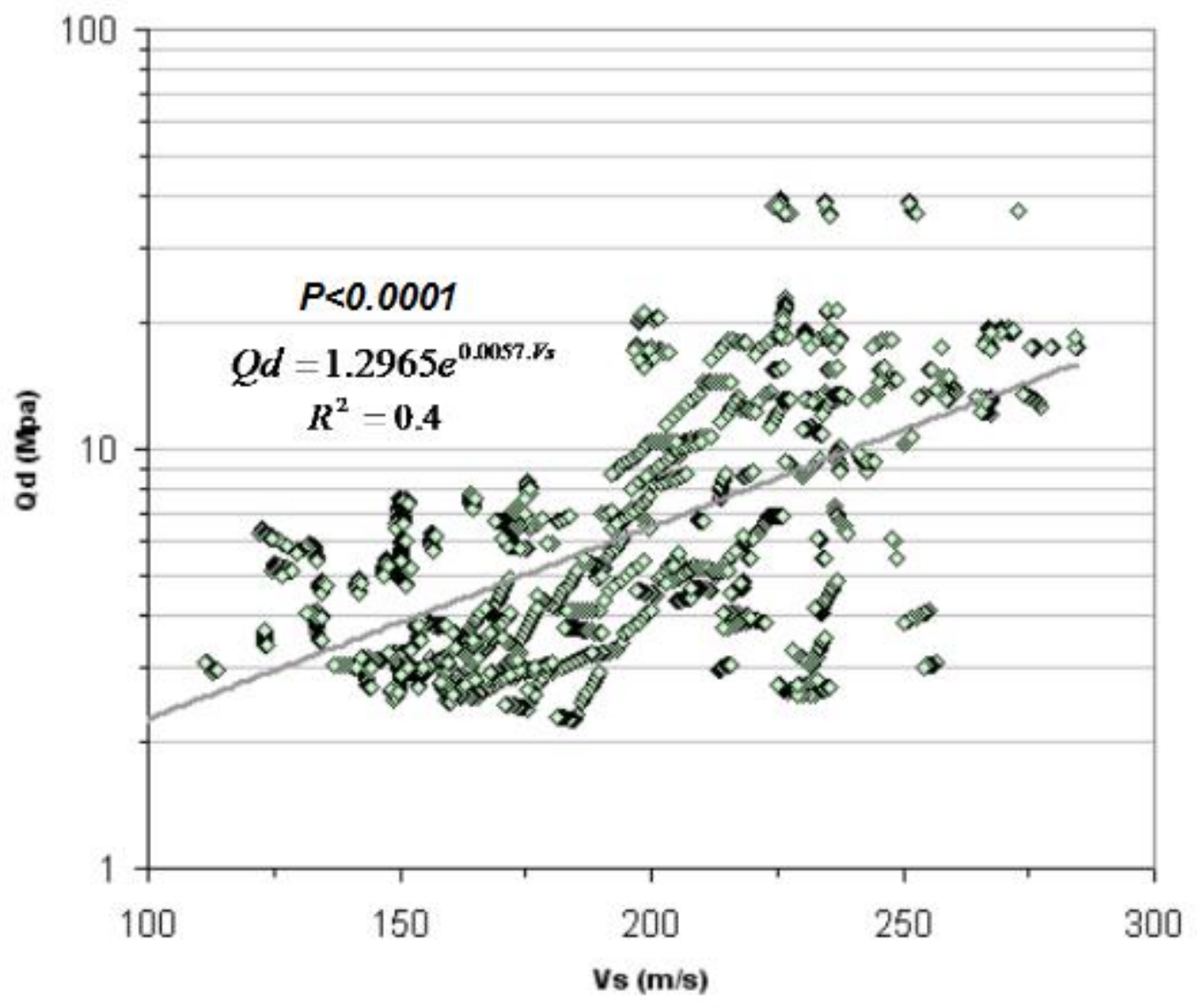

816

817 
Figure 10
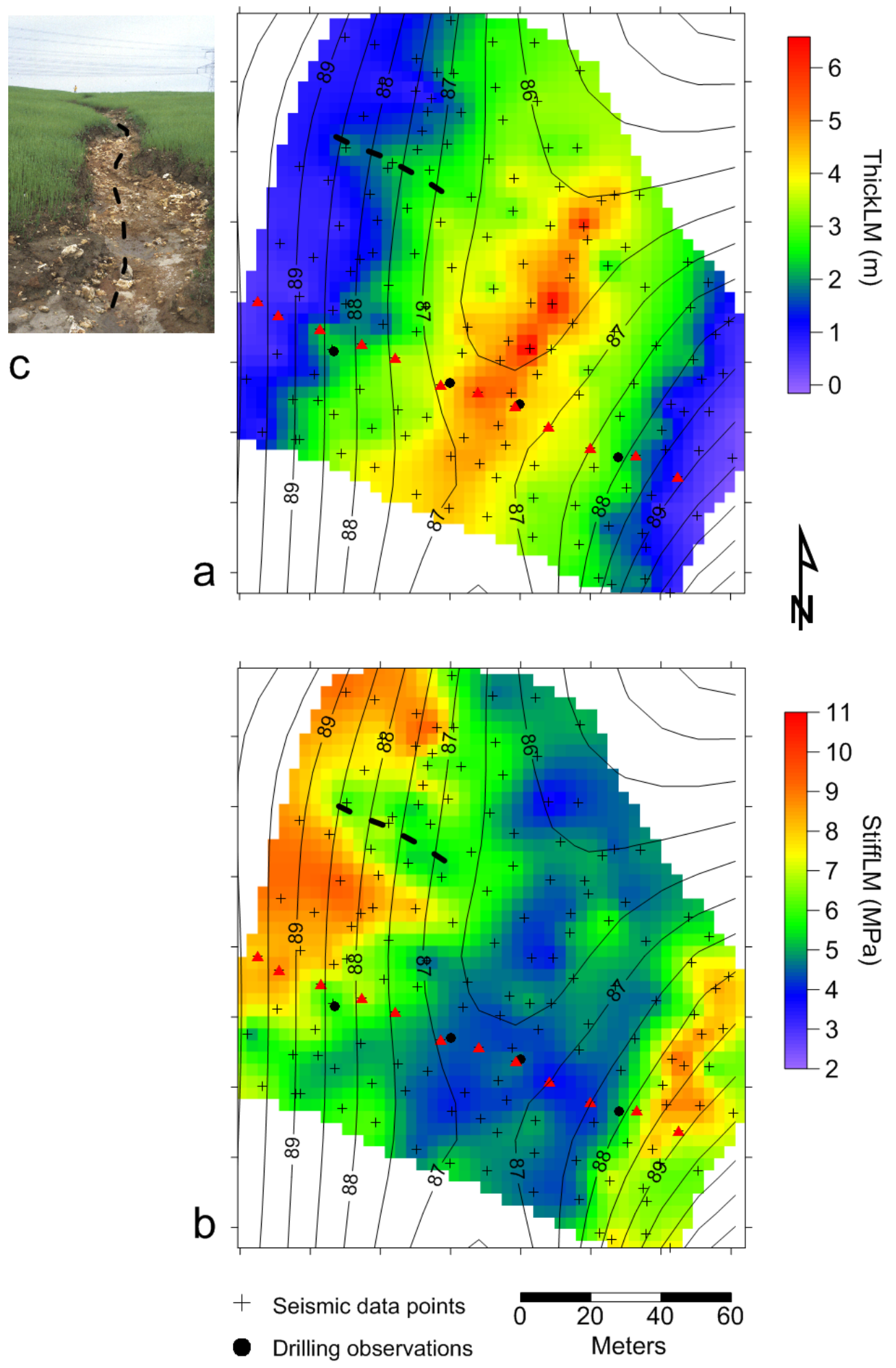

- Penetrometric soundings 
Figure 11

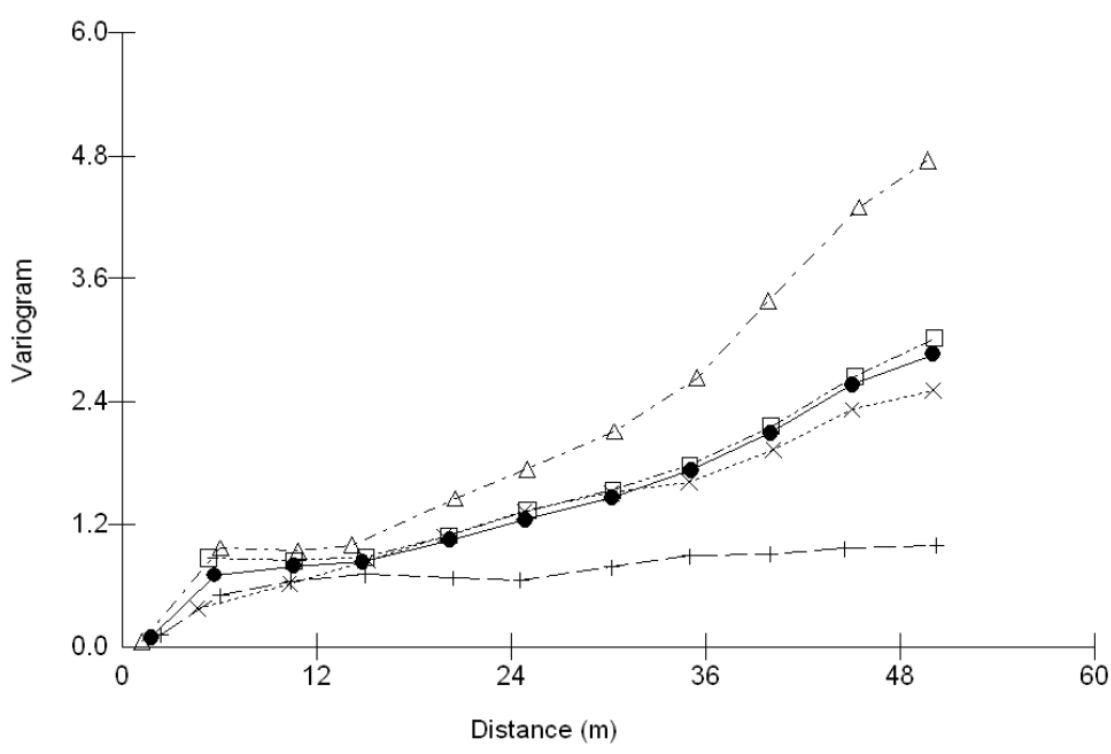

$+20^{\circ}$

$\times 65^{\circ}$

$\triangle 110^{\circ}$

$\square 155^{\circ}$

- Isotropic

a

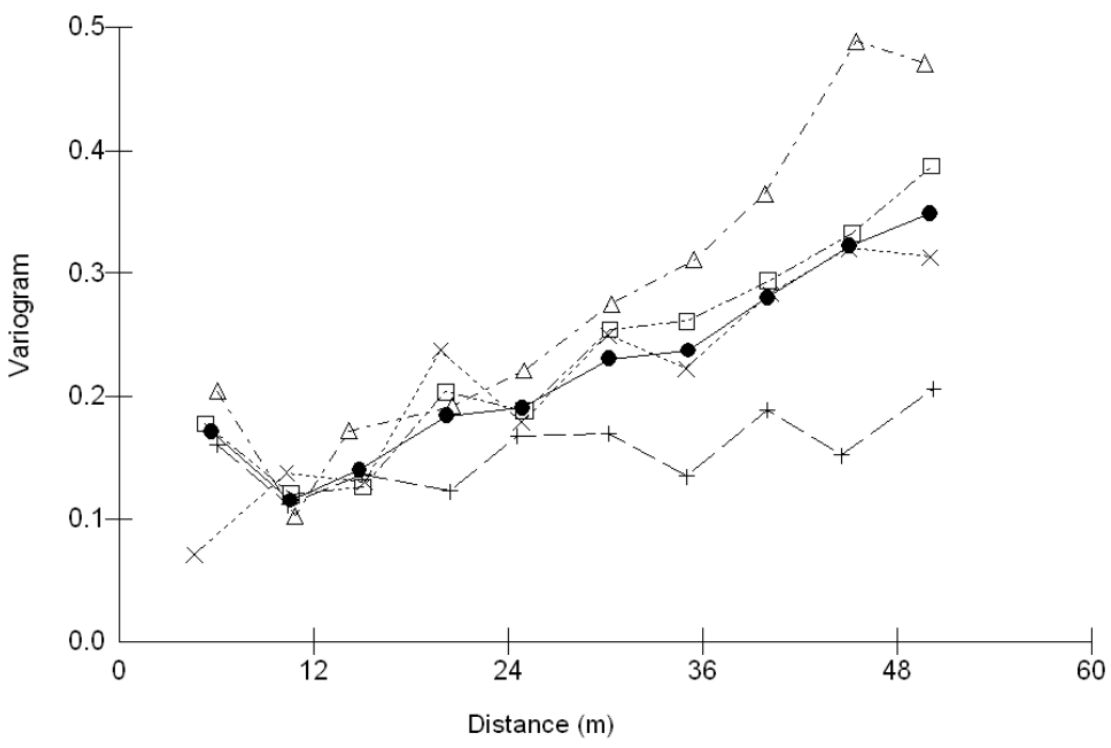

$+20^{\circ}$

$\times 65^{\circ}$

$\triangle 110^{\circ}$

$\square 155^{\circ}$

- Isotropic

b 
$824 \quad$ Figure 12

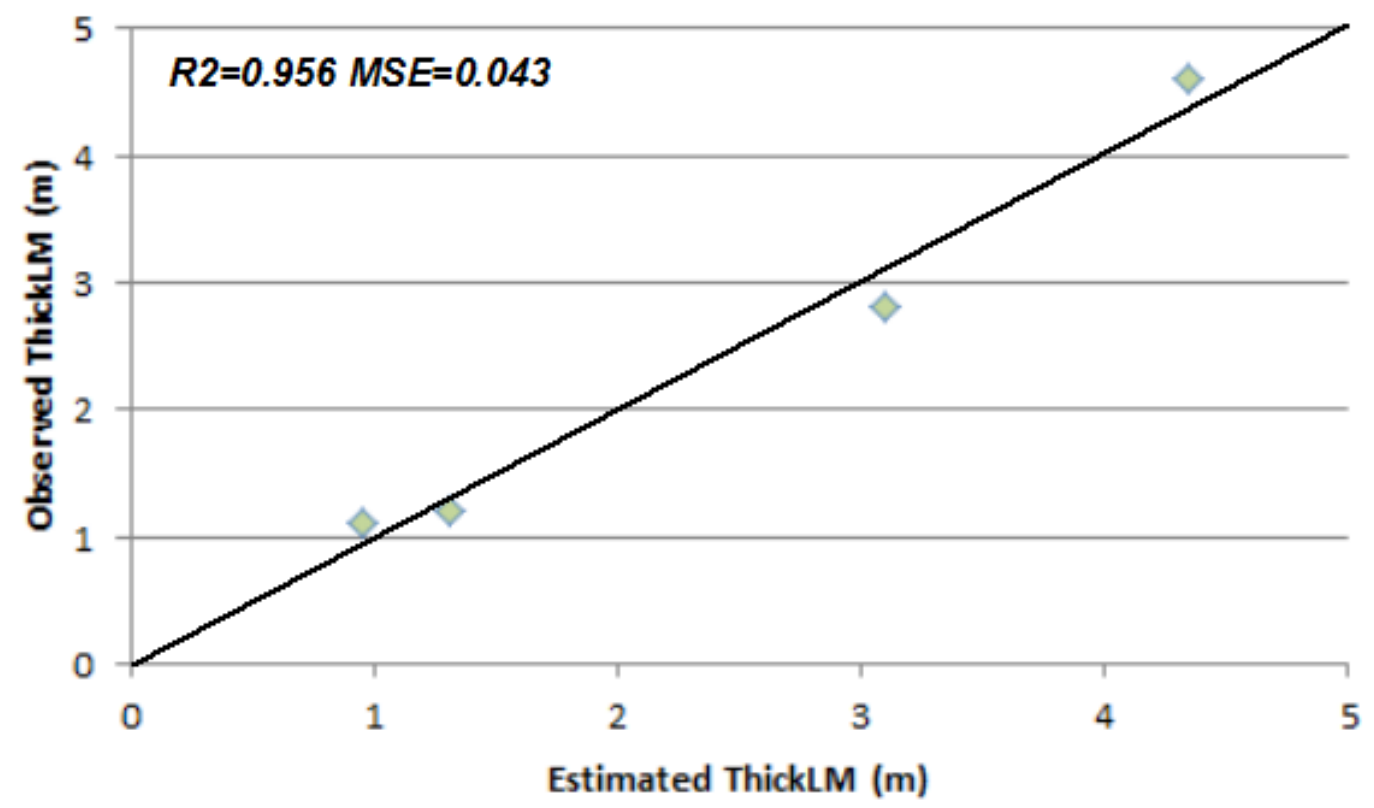

825 